\title{
A Pilot Study on the Muscle Activities in Step Input Test as an Indicator of the Vehicle Characteristics
}

\author{
Yong-Ku Kong ${ }^{1}$, Myung-Chul Jung ${ }^{2}$, In-Seok Lee ${ }^{3}$, Young-Jin Hyun ${ }^{4}$, \\ Chang-Su Kim ${ }^{4}$, Min-Tae Seo ${ }^{1}$ \\ ${ }^{1}$ Department of Industrial Engineering, Sungkyunkwan University, Suwon, 440-746 \\ ${ }^{2}$ Department of Industrial Engineering, Ajou University, 443-749 \\ ${ }^{3}$ Department of Civil, Safety and Environmental Engineering, Hankyong National University, Anseong, 456-749 \\ ${ }^{4}$ Hyundai $\cdot$ Kia Motors, Hwaseong, 445-706
}

\begin{abstract}
Objective: The purpose of this study was to analyze 'response time', 'peak response time' and 'overshoot value' for each muscle by applying the EMG signal to the vehicle response in ISO 7401 and to quantify the response of the driver according to vehicle characteristics by comparing vehicle characteristics and muscle responses of the driver. Background: The Open-loop test defined in international standards ISO 7401 is the only method for evaluating the performance of the vehicle. However, this test was focused only on mechanical responses, not driver's ones. Method: One skilled male driver(22 yrs. experience) was participated in this experiment to measure muscle activities of the driver in transient state. Then the seven muscle signals were applied to calculate 'response time', 'peak response time', and 'overshoot value'. Results: In the analyses of the EMG data, the effects of vehicle type and muscle were statistically significant on the 'response time' and 'peak response time'. Also, the effects of vehicle type, muscle, and lateral acceleration level were statistically significant on the 'overshoot value' in this study. According to the analyses of the vehicle motion data, vehicle motion variable(LatAcc, Roll, YawVel) was statistically significant on the 'response time' and vehicle type, vehicle motion variable, and lateral acceleration level were statistically significant on the 'peak response time', respectively. Conclusion: In the analyses of the 'response time' and 'overshoot value', the data of muscle activities(EMGs) was better index that could evaluate the vehicle characteristic and performance than the data of vehicle motion. In case of peak response time, both EMG and vehicle motion data were good index. Application: The EMGs data from a driver might be applicable as index for evaluation of various vehicle performances based on this study.
\end{abstract}

Keywords: EMG, Vehicle motion, Response time, Peak response time, Overshoot value

\section{Introduction}

자동차 산업의 발전으로 차량의 성능을 평가하기 위한 연 구에 많은 관심이 모아지고 있다. 특히 고출력과 고성능화
를 위해 개발된 $\mathrm{ABS}$ (Anti-lock Brake System), 4WS (4-Wheel Steering), TCS(Traction Control System), ECS(Electronic Controlled Suspension) 등과 같은 능동적 안전(Active Safety) 시스템들의 출현으로 인하여 능동적인 안전성의 향상은 새로운 연구과제로 부각되고 있다(Senger

Corresponding Author: Min-Tae Seo. Department of Industrial Engineering, Sungkyunkwan University, Suwon, 440-746.

Mobile: +82-10-8000-9284, E-mail: smt850920@skku.edu

Copyright@2013 by Ergonomics Society of Korea(pISSN:1229-1684 eISSN:2093-8462). All right reserved.

(c) This is an open-access article distributed under the terms of the Creative Commons Attribution Non-Commercial License(http://creativecommons.org/licenses/by-nc/3.0/), which permits unrestricted non-commercial use, distribution, and reproduction in any medium, provided the original work is properly cited. http://www.esk.or.kr 
and Schwartz, 1987; Takiguchi and Yasuda, 1988).

이러한 시스템의 개발과 더불어 차량의 성능을 정량적으 로 평가하기 위하여 차량 성능 시험에 대한 국제 표준들 (ISO 4138/9816/ 7975/3888/8725/8726/ 7401 등) 을 여러 연구에서 많이 활용하고 있다(Yoon et al., 1994; Sohn et al., 1995; Data and Frigerio, 2002; Yi et al., 2004; Svensen and Hac, 2005; Kang et al., 2011; Gobbi et al., 2012). 그 중, 과도 상태에서의 차량 응답을 평가하기 위한 ISO 7401:2003은 Open-loop 시험에 대한 시험 과정 및 분석 방법을 자세히 명시해 놓았다. Open-Loop 시험이란, 시간의 흐름을 기반으로 하는 step input 시험으로 초기 설 정된 속도로 일정하게 주행하고 미리 선정된 횡 가속도에 알 맞은 조향 입력을 신속히 가하여 차량이 과도 응답을 지나 정상 상태에 도달할 때까지의 조타 각을 수초간 유지하는 주 행 시험이다. 결국, 이 시험의 목적은 step input에 따른 차 량의 반응을 평가하기 위함이다.

최근 step input 시험과 같은 차량의 성능을 평가하기 위 한 여러 상용화된 주행 시험 방법들은 실제 운전자가 아닌 Steering wheel robot, load cell, and gyroscope censor system과 같은 전문 측정 장비 (Babala et al., 2002; Ryu and Gerdes, 2004)를 사용하여 차량으로부터 나오는 정량 적인 데이터를 수집하여 분석하고 있지만, 실제 차량을 사용 하고 주행하는 것은 운전자의 몫이기 때문에 조종성 및 안전 성 등에 대해 연구에서는 차량과 운전자 모두에 해당하는 객 관적이고 정량화된 데이터를 정확하게 수집하여 분석하기 위해서는 운전자를 고려한 연구의 시도가 필요하다고 할 수 있다.

기존의 여러 연구들이 ISO 7401을 바탕으로 하여 Openloop 조건에서의 차량 성능 평가를 시행하였으나(Yoon et al., 1994; Shon et al., 1995; Data and Frigerio, 2002; Yi et al., 2004), Open-loop 시험은 차량 자체의 특성만을 다 루는 시험 방법이므로 운전자를 함께 고려하여 종합적인 평 가로는 한계가 있다. 그 이유로는 차량의 동적 특성이 정량 적으로 높은 평가를 받았다 하더라도 실제 운전자가 느끼는 평가는 다를 수 있기 때문이다. 이와 같은 이유로 본 연구에 서는 차량만을 고려한 Open-loop 시험에서, 운전자 근육의 활성도를 평가할 수 있는 근전도를 적용하고자 한다. 근전도 시스템을 적용한 이유로는 외부로부터의 물리적 작용이 발 생할 경우, 운전자는 자세 유지 및 조작을 위해 근육을 사용 하기 때문에 보다 명확한 결과가 도출될 것이라 기대하였기 때문이다.

Pick and Cole(2006)의 연구는 시뮬레이션 차량 성능 시험에서 삼각근, 대흉근, 상완이두근, 그리고 상완삼두근 의 근육 신호를 측정하여 근육의 활성도를 분석하였고, Balasubramanian and Adalarasu(2007)의 연구에서는 시
뮬레이션 주행 시험 동안의 측면삼각근와 상부승모근의 근 전도 신호를 측정하여 근육의 피로도를 분석하였다. 이처럼 기존 연구에서 주행 시뮬레이터를 이용하여 차량과 운전자 를 평가하였지만 실제 주행은 차량의 움직임에 따라 운전자 에게 물리적 힘이 적용되기 때문에 시뮬레이션 주행과는 다 소 상이한 결과가 나타날 가능성을 배제할 수 없을 것이다.

Step input 시험에서 수집된 차량 관련 데이터는 기초 적으로 5 가지 차량거동인 steer wheel angle(SWA), lateral acceleration(LatAcc), roll angle(Roll), yaw velocity (YawVel)로 이 차량거동은 다시 3가지 차량 반응 (Response time, Peak response time, Overshoot value) 으로 각각 분석할 수 있다(ISO 7401, 2003).

본 연구의 목적으로는 (1) ISO 7401에 나타나 있는 차 량 신호 분석 방법에 근전도 신호를 적용하여 조향에 따른 근육 별 response time, peak response time, overshoot value를 계산하고 분석하는 것이고, (2) 그 결과를 바탕으로 차량 특성 (차량A와 차량 $\mathrm{B}$ ) 간의 비교와 운전자 근육 반응 에 대한 비교를 통해 차량 특성에 따른 운전자의 반응을 정 량화 하고자 한다. (3) 또한, 최종적으로 근전도 시스템이 차 량 특성 또는 중력가속도를 규명할 수 있는 지표로 활용이 가능 한지를 파악하고자 한다.

마지막으로 본 연구의 결과를 바탕으로 하여 운전자 특성 및 차량 특성 파악을 보다 간략하고 명확하게 할 수 있는 선 행연구로써 활용되길 기대한다.

\section{Methods}

\subsection{Participants}

실험에 참가한 피실험자는 23 년의 운전 경력을 가지고 있 는 전문 운전자 $(45$ 세, $173 \mathrm{~cm}, 73 \mathrm{~kg}$ )로 선정하였으며, 상지 및 하지에 근골격계 관련 질환의 진단 경력을 가지고 있지 않았다. 차량 반응에 따른 인체의 반응을 알아보고 실험의 방향성을 확인하기 위하여 진행한 선행연구이기 때문에 전 문드라이버 한 명을 선정하여 실험을 진행하였다.

\subsection{Apparatus}

세 가지 중력가속도 $(0.1 \mathrm{~g}, 0.5 \mathrm{~g}, 0.8 \mathrm{~g})$ 에 따른 step input 주행에서 두 가지의 차량 특성에 따라 차량 반응과 인체 반 응에 어떠한 차이가 있는지 알아보기 위해 hatchback 타입 의 중형 승용차 2 대를 실험에 사용하였다. 이 때, 두 승용차 의 차종 및 성능은 동일하였고, 타이어 휠의 지름 (A: $15 ", \mathrm{~B}$ : $17 ")$ 과 스테빌라이져 바(Stabilizer bar)의 지름(A: $18 \mathrm{~mm}$, 
$\mathrm{B}: 16 \mathrm{~mm}$ )만 상이하게 하여 실험을 하였다. 타이어 휠과 스 테빌라이져 바를 두 가지로 다르게 조합하여 차량 $\mathrm{A}$ 와 $\mathrm{B}$ 에 각각 다르게 적용하면, 차량의 LatAcc, Roll, YawVel이 차 이가 나므로 이 두 가지를 변수로 선정하였다. Table 1은 $\mathrm{A}$ 차량과 $\mathrm{B}$ 차량의 특징을 나타낸다. 차량의 핸들링 특성에 서 언더스티어는 운전자가 정상(neutral steer) 수준 보다 조향을 더 많이 필요로 하는 특성을 의미하며, 오버스티어는 정상 수준 보다 조향을 덜 해도 차가 빠르게 반응하며, 상대 적으로 다이나믹한 주행을 하는 현상을 의미한다. Figure 1 은 주행 특성을 나타낸다.

Table 1. Specification of vehicle A and B

\begin{tabular}{c|c|c}
\hline Vehicle type & A & B \\
\hline Tire(Inch) & 15 & 17 \\
\hline Stabilizer bar $\Phi(\mathrm{mm})$ & 18 & 16 \\
\hline Handling characteristic & Under steer & Over steer \\
\hline
\end{tabular}

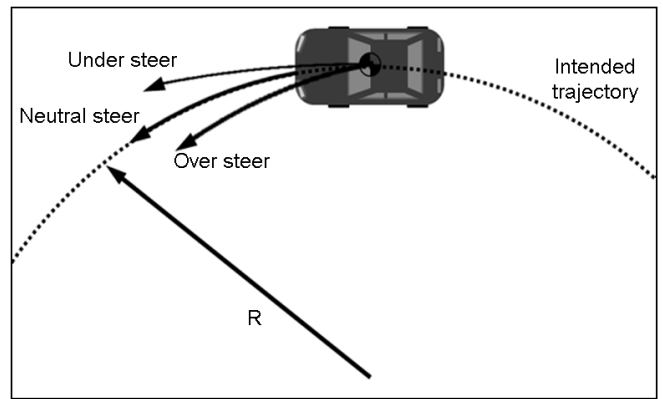

Figure 1. Three handling characteristics (Williams and Haddad, 1995) [R: Radius of curvature]

피실험자에게 주행 환경의 일관성을 유지시키기 위해 두 차량 내부의 온도는 약 $22^{\circ} \mathrm{C}$ 로 동일하게 유지시켰다. TeleMyo 2400DTS telemetry system (Noraxon U.S.A., gain $=500$; noise $\langle 1 \mu \mathrm{V}$, sampling rate $=1,500 \mathrm{~Hz})$ 을 이용해 근전도 신호를 수집하였고 $10 ~ 500 \mathrm{~Hz}$ 대역으로 필 터링 하였다. 모든 데이터는 $16 \mathrm{bit}$ 로 수집되어 디지털 변 환기를 통해 노트북에 저장되었다. 다섯 가지의 차량거동 변수: Steer angle(SWA), lateral acceleration(LatAcc), roll angle(Roll), yaw velocity (YawVel)를 수집하기 위해 DEWE-5000-PM(Dewetron, Austria) 데이터 수집 시스 템을 이용하였다. Figure 2은 The Society of Automotive Engineers (SAE 1976)에서 정의하고 있는 차량 축 시스 템을 나타낸다(Milliken and Milliken, 1995). 데이터는 16 비트 아날로그 신호로 디지털 변환기를 통해 $300 \mathrm{~Hz}$ 의 sampling rate로 수집되었다. 또한, 차량 관련 데이터는 trigger button of analog output receiver(TeleMyo 2400R G2, NORAXON, USA) 의 5 millivolt input TTL signal을 이용해 운전자의 근육에 대한 데이터인 근전도 신호와 동기 화하였다. Figure 3은 데이터 측정 시스템과 동기화 과정을 나타낸다.

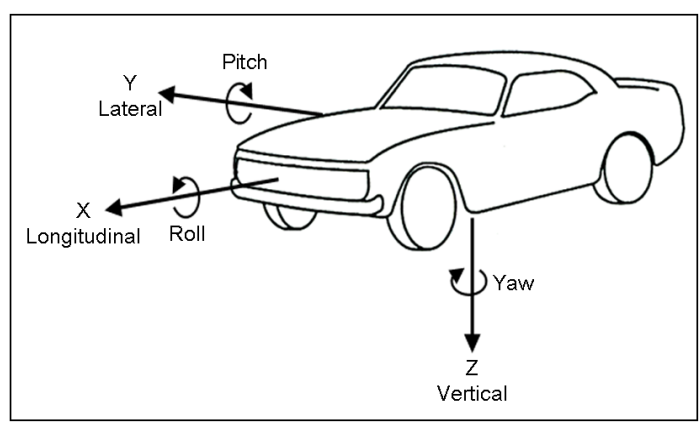

Figure 2. Vehicle axis system defined by the Society of Automotive Engineers(Milliken and Milliken, 1995)

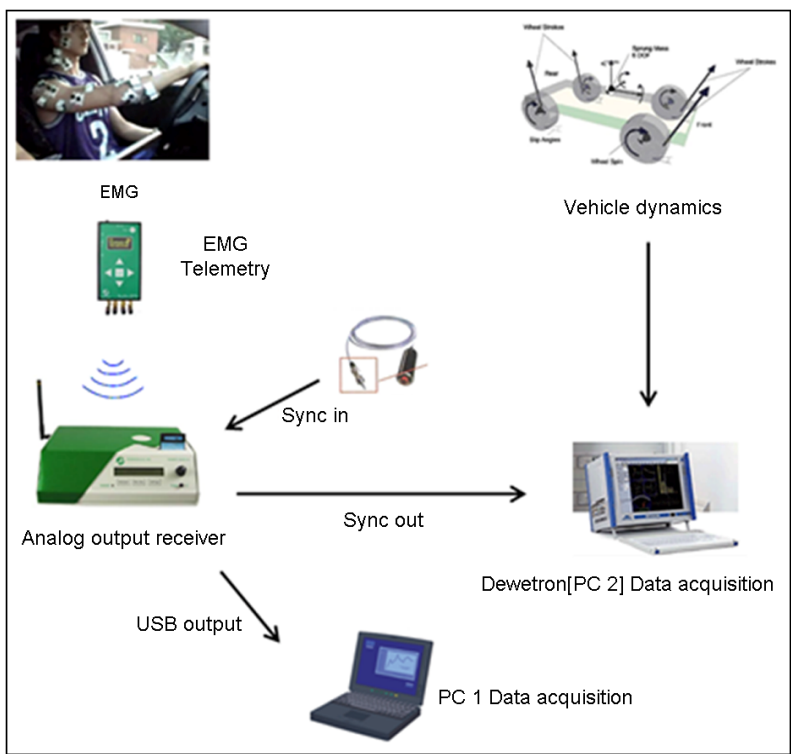

Figure 3. Apparatus and data sync processing

\subsection{Procedure}

과도 상태에서의 차량과 근육의 반응을 규명하기 위한 한 가지 방법으로서 ISO 7401:2003에 정의되어 있는 step input 시험을 실시하였다(Figure 4). 차량의 주행속도를 80 $\mathrm{kph}$ 로 유지하도록 하고, 정상 상태(Steady-state) 도달 시 
$0.1,0.5,0.8 \mathrm{~g}$ 의 횡 가속도가 되도록 정상 상태 원형 주행 시험에서 조향 각의 크기를 결정한 후, 주행 시험을 수행하 였다. 이 때, 중립의 조향 각에서 각 횡 가속도에 해당하는 조향 각까지 핸들링하는 시간은 $0.15 \mathrm{~s}$ 을 넘지 않도록 하였 다. 정확한 측정을 위하여 조향 각이 입력된 후에는 핸들을 일정하게 유지시켜 시험을 수행하였다. $\mathrm{A}$ 차량과 $\mathrm{B}$ 차량 모 두 동일하게 $80 \mathrm{kph}$ 의 속도에서 세 가지 중력가속도 $(0.1 \mathrm{~g}$, $0.5 \mathrm{~g}, 0.8 \mathrm{~g})$ 를 무작위로 각각 3 회 반복하였으며, 피로 효과 를 최소화하기 위해 반복 사이에는 약 3 분의 휴식을 취하였 다. 또한 실험에 익숙해지기 위해 피실험자는 근전도 센서 를 부착한 상태로 본 실험에 앞서 ISO 7401:2003의 step input 시험 주행 가이드라인을 따라 3 회 이상 충분히 연습 후에 본 실험을 수행하였다.

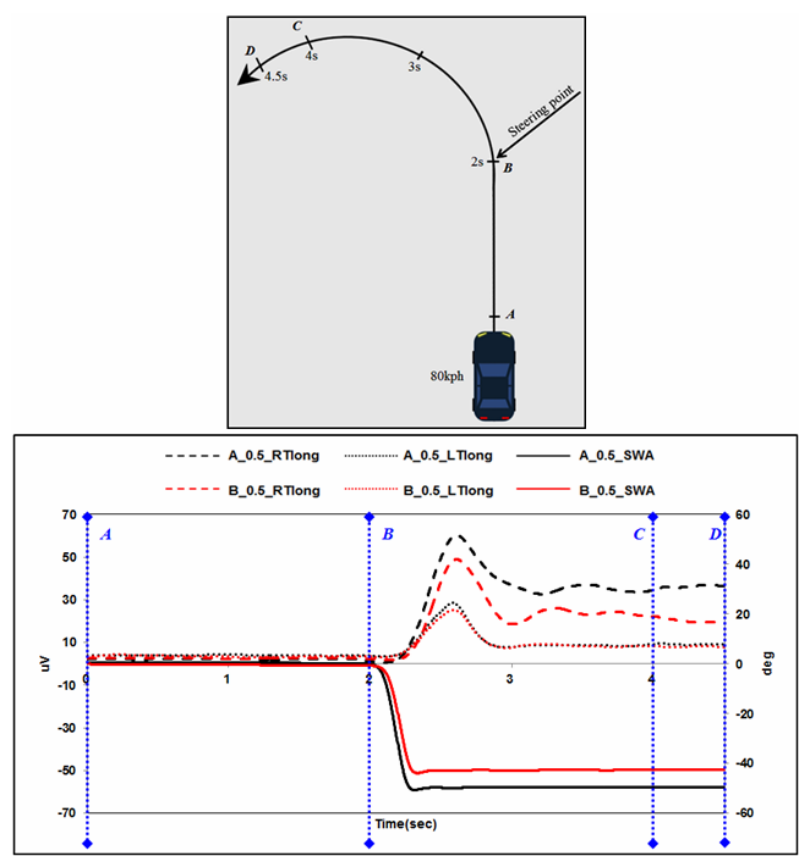

Figure 4. Step input test and defining section of recording signal (ISO 7401:2003) [A: Before 2s of steering point, B: Steering point, C: After $2 \mathrm{~s}$ of steering point, $\mathrm{C} \sim \mathrm{D}$ : Steady-state section]

파일럿 테스트 결과를 통해 본 실험에서 평가하는 7 가지 상지와 하지의 근육으로는 우측 측면삼각근(RMD), 우측 후 면삼각근(RPD), 좌측 대흉근(LPMS), 우측 상완삼두근 장 두(RTlong), 좌측 상완삼두근 장두(LTlong), 좌측 대퇴직근 (LRF), 우측 장비골근(RPL)이며, SENIAM(Hermens et al., 1999) 과 Perotto et al.(2005)에 따라 근전도 전극을 Figure 5와 같이 부착하였다.

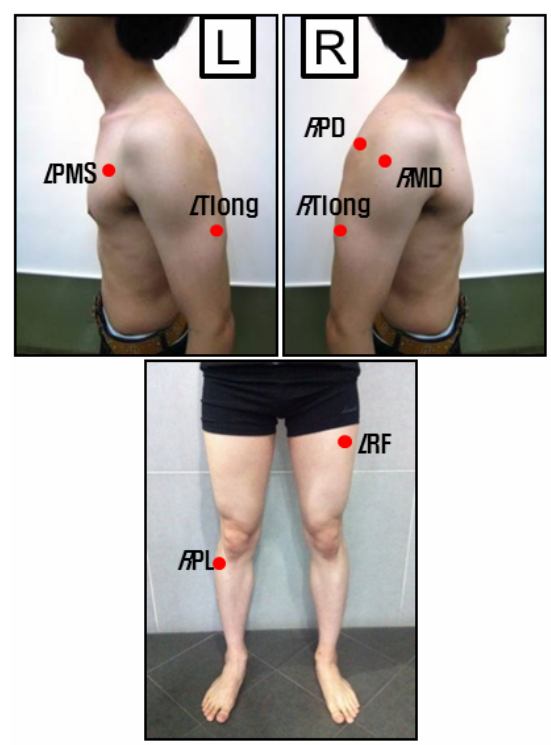

Figure 5. Positions of EMG electrodes(Hermens et al., 1999; Perotto et al., 2005) [Right Middle Deltoid(RMD), Right Posterior Deltoid(RPD), Left Pectoralis Major Sternal(LPMS), Right Triceps brachii Long head(RTlong), Left Triceps brachii Long head(LTlong), Left Rectus Femoris(LRF), Right Peroneus Longus(RPL)]

\subsection{Signal processing}

기록된 차량거동 신호와 근전도 신호에서 $0 \sim 4.5$ 초 구간을 추출하여 분석에 사용하였다. 즉, Figure 4에서 step input의 시작 2 초 전 지점을 $\mathrm{A}$, 시작 지점을 $\mathrm{B}$, 시작 2초 후 지점을 $\mathrm{C}$, 그리고 이후 정상 상태 구간인 마지막 0.5 초 지점을 $\mathrm{D}$ 로 정의하여 신호를 분석하였다. 이는 ISO 7401:2003에서 step input 분석 방법을 참고하여 차량거동과 근육활성도 신 호를 $\mathrm{A}$ 지점에서 $\mathrm{D}$ 지점까지의 구간을 분석하기 위해 추출된 신호이다.

근전도 신호의 처리는 초기 $\mathrm{EMG}$ 신호에서 $\mathrm{ECG}$ 신호 를 제거하였고(USA Inc., Scottsdale, Arizona), linear envelope으로 변환하기 위해 이후 차량거동 신호와 근전도 신호를 dual pass Butterworth low pass filter를 이용하여 $2 \mathrm{~Hz}$ 로 필터링 하였다(Hermens et al. 1999, Winter 2005).

\subsection{Experimental design}

과도 상태에서 차량 응답 특성을 규명하기 위해 차량거동 을 측정하였고, ISO 7401:2003에 정의되어 있는 response time, peak response time, overshoot value에 대해 각각 계산하였다. 또한 본 연구에서는 운전자를 고려하기 위하 여 근전도 신호의 response time, peak response time, 
overshoot value를 차량거동과 동일한 방법으로 도출하여 분석하였다(Table 2과 Figure 6).

Table 2. Definitions of variables

\begin{tabular}{l|c}
\hline & Vehicle motion \& EMG \\
\hline Rsponse time & $\begin{array}{c}\text { Time of first reach 90\% of its steady state - } \\
\text { Reference point }\end{array}$ \\
\hline Peak response time & $\begin{array}{c}\text { Time of first reach to peak - Reference point } \\
\text { Overshoot value }\end{array}$ \\
\hline
\end{tabular}

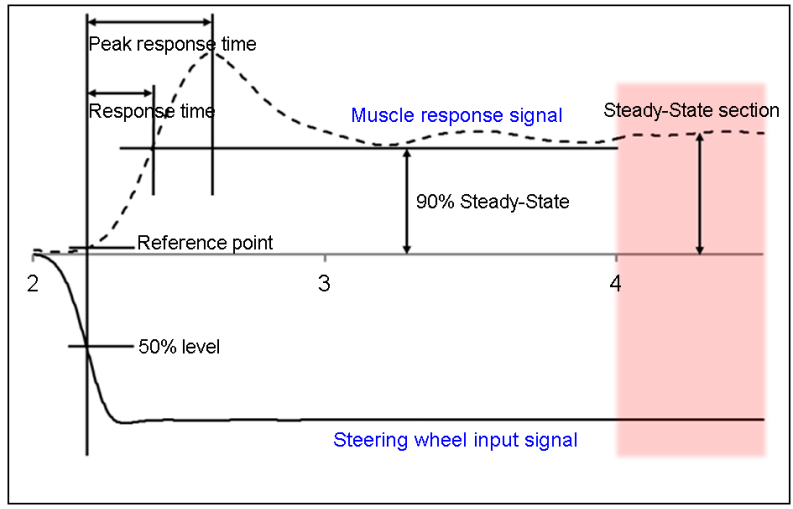

Figure 6. Graph of EMG response by applying Step input test

종속변수인 response time, peak response time, overshoot value에 대한 차량거동의 독립변수로는 차량 특성 (2수준: 차량 $\mathrm{A}$, 차량 $\mathrm{B}$ ), 차량거동 (3수준: LatAcc, Roll, YawVel) 그리고 중력가속도(3수준: $0.1 \mathrm{~g}, 0.5 \mathrm{~g}, 0.8 \mathrm{~g}$ )로 선정하였으며, 근육에 대한 독립변수는 차량 특성 (2수준: 차량 $\mathrm{A}$, 차량 $\mathrm{B}$ ), 근육 (7수준: RMD, RPD, LPMS, RTlong, LTlong, LRF, RPL) 그리고 중력가속도(3수준: $0.1 \mathrm{~g}, 0.5 \mathrm{~g}$, $0.8 \mathrm{~g})$ 를 선정하였다.

통계적 분석 패키지는 SPSS 18.0을 사용하였고, 통계적 유의수준 $(\alpha)$ 은 0.05 로 선정하였다. 사후분석은 Tukey HSD test를 수행하였다.

\section{Results}

\subsection{Response time}

\subsubsection{Response time of EMG data}

상지와 하지의 7 개 근육에서 수집된 근전도 신호의
Response time에 대한 분석 결과, 주 효과인 차량 특성과 근육, 그리고 차량 특성과 근육의 교호작용이 통계적으로 유 의한 차이를 보였으나(All $p$-values < 0.05), 중력가속도에 따른 근전도 신호는 response time의 결과에서 통계적인 차 이를 보이지 않았다.

차량 특성에 따른 response time에서는 $\mathrm{B}$ 차량의 response time은 0.16s로 A 차량의 $0.2 \mathrm{~s}$ 보다 통계적으로 빨랐으며, 근육 별 결과로는 우측 어깨 근육인 $\mathrm{RMD}$ 근육의 response time (0.09s)이 가장 빨랐으며, LTlong(0.11s), RPD (0.14s), LPMS (0.18s), RTlong(0.19s), 그리고 RPL (0.20s) 근육들이 그 뒤를 이었다. 좌측 장딴지 근육인 $\mathrm{LRF}$ 근육은 0.32s으로 가장 느린 response time을 보였다 (Figure 7).

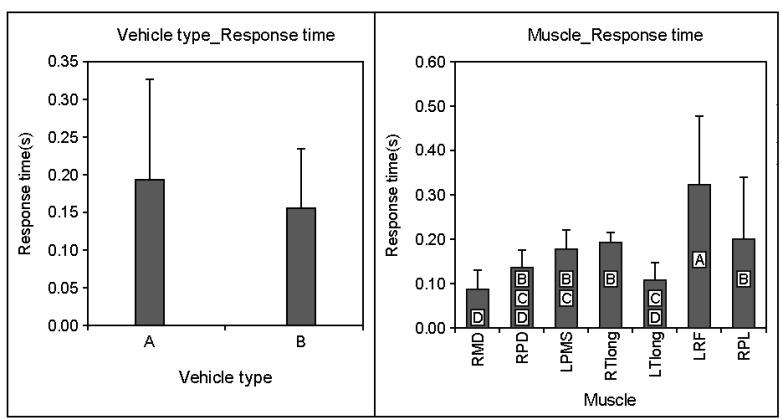

Figure 7. Response time of EMG for vehicle type and muscle [alphabetic letters denote significant groupings, $\alpha=0.05$ ]

차량 특성과 근육 간의 교호작용 또한 통계적으로 유의한 결과 $(p=0.001)$ 를 보였는데, 일반적으로 상지의 근육들의 경우에는 차량 특성에 따라 통계적으로 유의한 차이를 보 이지 않는 반면, 하지 근육인 대퇴직근(LRF)에서 $\mathrm{B}$ 차량 $(0.22 \mathrm{~s})$ 의 response time이 A차량(0.42s)의 response time보다 통계적으로 유의하게 빠르게 나타났다 $(p=0.019)$. 또 다른 하지 근육인 우측 장비골근(RPL) 역시 $\mathrm{LRF}$ 근육 과 유사한 경향(즉, 차량 $\mathrm{B}: 0.16 \mathrm{~s}$; 차량 $\mathrm{A}: 0.20 \mathrm{~s}$ )을 보여 주고 있으나, 통계적으로 유의하지는 않았다. 따라서 본 실 험 결과에 의하면, 차량 특성을 비교적 명확하게 반영하는 근육은 상지의 근육보다는 하지의 근육, 특히 $\mathrm{LRF}$ 근육이라 고 할 수 있을 것이다. Figure 8은 차량 특성과 근육 간의 교호작용에 대한 그래프이다.

\subsubsection{Response time of vehicle motion data}

차량거동 신호 데이터의 response time에 대한 분석에서 는 오직 차량거동 변수만이 통계적으로 유의함을 보였으며 $(p<0.0001)$, 차량 특성과 중력가속도에 따른 차량거동 신 
호는 통계적 차이를 보이지 않았다. Figure 9는 차량거동 변수의 주 효과에 대한 그래프이다. YawVel은 가장 빠른 response time을 보였고, LatAcc와 Roll은 서로 통계적 차 이를 보이지 않았다.

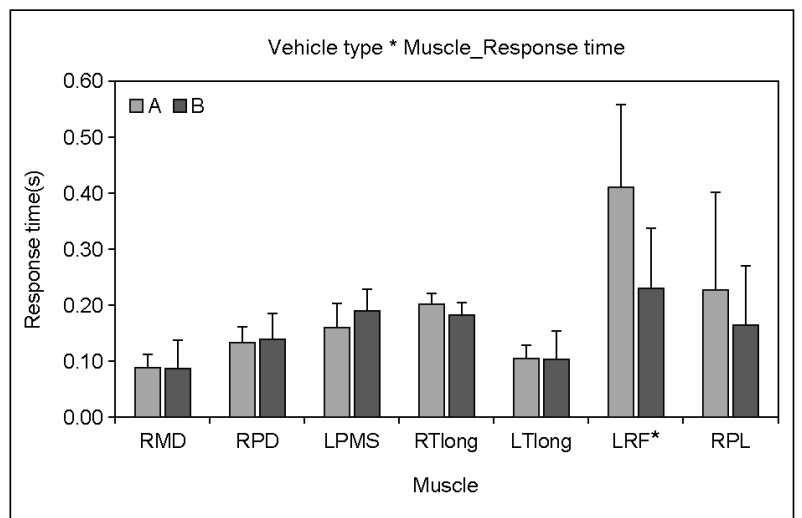

Figure 8. Interaction effects of vehicle type and muscle $\left[{ }^{*}\right.$ denotes the statistically significance: i.e., $\left.p<0.05\right]$

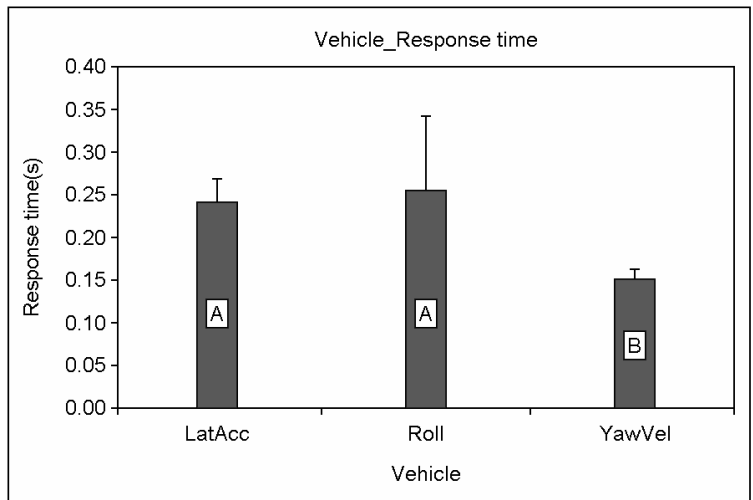

Figure 9. Response time of vehicle motion data [alphabetic letters denote significant groupings, $\alpha=0.05$ ]

\subsection{Peak response time}

\subsubsection{Peak response time of EMG data}

근전도 데이터에 대한 peak response time의 ANOVA 분석 결과, 차량 특성 $(p=0.037)$ 과 근육 $(p<0.0001)$ 에 따 라 통계적으로 유의하게 나타났다. Response time 분석 결 과(3.1.1)와 유사하게, 차량 특성에 따른 B 차량의 peak response time(0.41s)이 A 차량(0.47s) 보다 더 빠르게 반응하였다. 근육에 따른 peak response time은 상지의 근육(RMD: 0.32s, RPD: 0.37, RTlong: 0.41s, LTlong: 0.37s, LPMS: 0.42s)이 하지의 근육(LRF: 0.63s, RPL: $0.57 \mathrm{~s})$ 보다 peak response time이 더 빠른 경향을 보였다 (Figure 10).

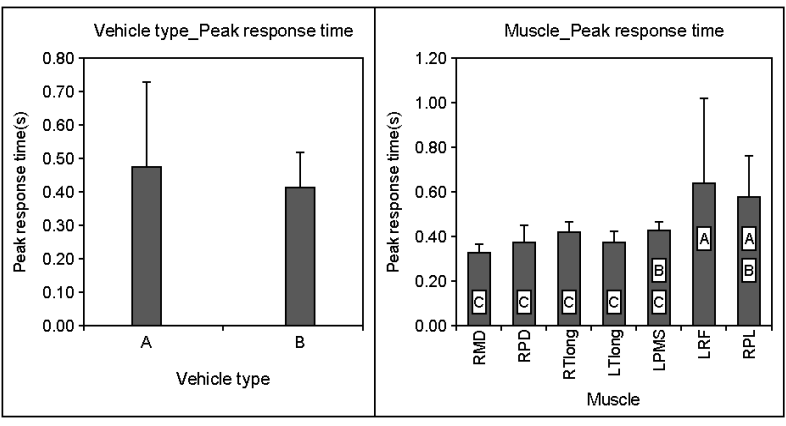

Figure 10. Peak response time of muscles [alphabetic letters denote significant groupings, $\alpha=0.05$ ]

\subsubsection{Peak response time of vehicle motion data}

Vehicle motion의 peak response time에 대한 분산분 석 결과로는 차량 특성 $(p=0.001)$, 중력가속도 $(p=0.010)$, 그리고 차량거동 $(p<0.0001)$ 에 따라서 peak response time 은 통계적으로 유의한 차이를 보였다. Figure 11에서 볼 수 있듯이, 차량 특성에 따른 peak response time은 $\mathrm{A}$ 차량 $(0.52 \mathrm{~s})$ 보다 B 차량 $(0.38 \mathrm{~s})$ 에서 더 빠르게 나타났다. 중력 가속도에 따른 Peak response time은 0.1g에서 0.39s, $0.5 \mathrm{~g}$ 에서 $0.40 \mathrm{~s}$ 로 나타났고 $0.8 \mathrm{~g}$ 에서 $0.52 \mathrm{~s}$ 의 peak response time으로 가장 느리게 반응하였다. Tukey test 결과로는 $0.1 \mathrm{~g}$ 와 $0.5 \mathrm{~g}$ 는 같은 그룹으로 분류되었다. 차량거동에 따른 peak response time은 YawVel(0.27s) 가 가장 빠른 peak response time을 보였고, LatAcc(0.46s)과 Roll(0.59s)이 그 뒤를 이었다. 이는 response time의 결과(Figure 9)와

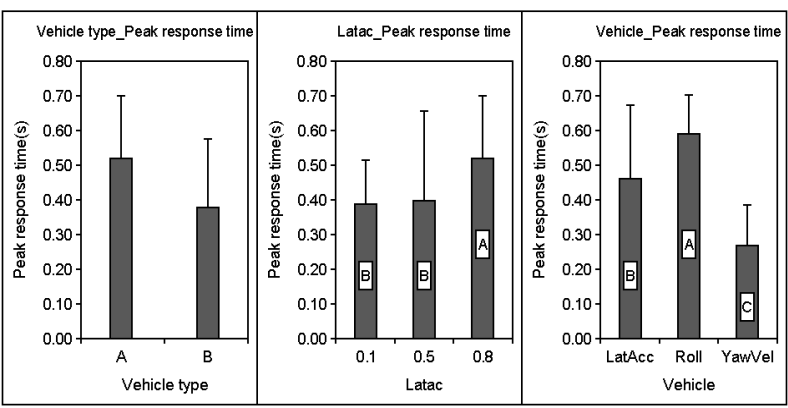

Figure 11. Peak response time of vehicle type, lateral acceleration level and vehicle motion data [alphabetic letters denote significant groupings, $\alpha=0.05$ ] 
매우 유사한 것을 알 수 있다.

\subsection{Overshoot value}

\subsubsection{Overshoot value of EMG data}

근전도 신호의 overshoot value에 대한 분산분석 결과, 차량 특성 $(p=0.013)$ 과 중력가속도 $(p<0.0001)$, 그리고 근 육 $(p<0.0001)$ 에 따라서 overshoot value는 통계적으로 유 의한 차이를 보였다. 차량 특성에 따른 overshoot value는 A 차량 $(125 \%)$ 에서 B 차량(89\%) 보다 높은 overshoot value가 나타났다. 중력가속도에 따른 overshoot value는 중력가속도가 증가할 수록 증가하는 경향을 보였다. 즉, $0.8 \mathrm{~g}$ (154\%)에서 가장 높았고, $0.5 \mathrm{~g}(111 \%), 0.1 \mathrm{~g}(39 \%)$ 가 그 뒤를 이었다. Tukey test 결과, 중력가속도 별 overshoot value는 모두 다른 그룹으로 분류되었다. 근육에 따른 overshoot value 분석에서는 비교적 상지 근육들(RMD: 165\%, RPD: 117\%, LPMS: 144\%, RTlong: 94\%, LTlong: $180 \%)$ 이 하지 근육들(LRF: $28 \%, \mathrm{RPL}: 7 \%$ )에 비해 높은 overshoot value가 나타났다(Figure 12).

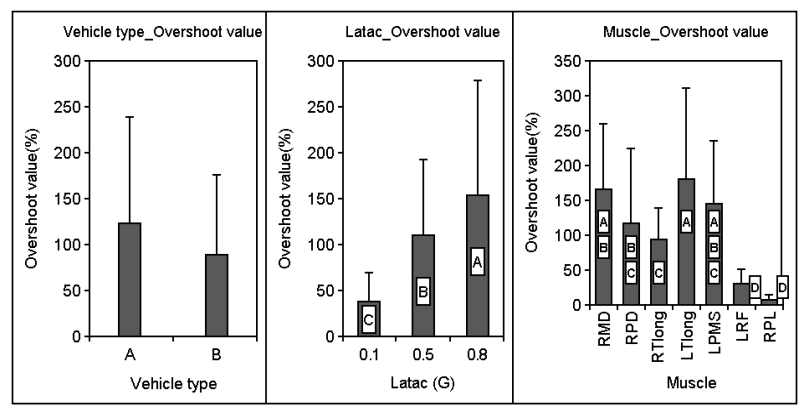

Figure 12. Overshoot value of vehicle type, lateral acceleration and muscles[alphabetic letters denote significant groupings, $\alpha=0.05]$

차량 특성과 중력가속도의 간의 교호작용에서 overshoot value는 통계적으로 유의한 결과를 보였다 $(p=0.001)$. 중력 가속도가 증가할 수록 $\mathrm{A}$ 차량과 $\mathrm{B}$ 차량의 overshoot value는 점차적으로 차이가 많이 나는 결과를 보였다. 즉, Figure 13 에서 보는 봐와 같이 중력가속도 $0.1 \mathrm{~g}$ 와 $0.5 \mathrm{~g}$ 에서의 $\mathrm{A}$ 차 량과 B 차량의 overshoot value는 서로 비슷하였으나, $0.8 \mathrm{~g}$ 에서는 A 차량의 overshoot value가 B 차량의 overshoot value 보다 비교적 높은 값을 보였다.

중력가속도와 근육 간의 교호작용에서도 overshoot value 는 통계적으로 유의한 결과를 보였다 $(p<0.0001)$. 이미 언 급한 봐와 같이, 전반적으로 하지의 근육들 보다 상지의 근

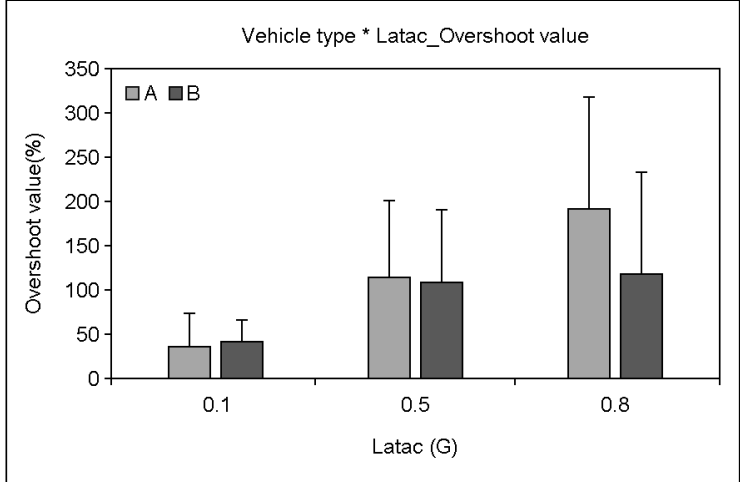

Figure 13. Interaction of vehicle type and lateral acceleration level

육들의 overshoot value가 높게 나타나는 경향을 보였으며, 특히 중력가속도가 증가함에 따라 이러한 경향은 두드러지게 나타났다[RMD (0.1g: 50.9\%, 0.5g: 208.0\%, 0.8g: 225.3\%), RPD (0.1g: 27.4\%, 0.5g: 124.7\%, 0.8g: 185.2\%), LTlong (0.1g: $72.5 \%, 0.5 \mathrm{~g}: 163.0 \%, 0.8 \mathrm{~g}: 284.0 \%)$, LPMS (0.1g: 49.9\%, 0.5g: 132.6\%, 0.8g: 232.1\%), LRF (0.1g: 15.9\%, 0.5g: 18.7\%, 0.8g: 46.3\%)].

특히, 우측 상완삼두근 장두(RTlong) 근육과 우측 장비골 근(RPL) 근육을 제외한 5 개의 근육 모두 중력가속도가 증 가함에 따라 overshoot value 또한 증가하여 중력가속도를 잘 반영하는 근육으로 나타났으며, 특히, Tukey test를 시 행한 결과, 가장 명확히 세 그룹으로 나뉘는 근육은 LPMS ( $p<0.0001)$ 근육으로 나타났다(Figure 14).

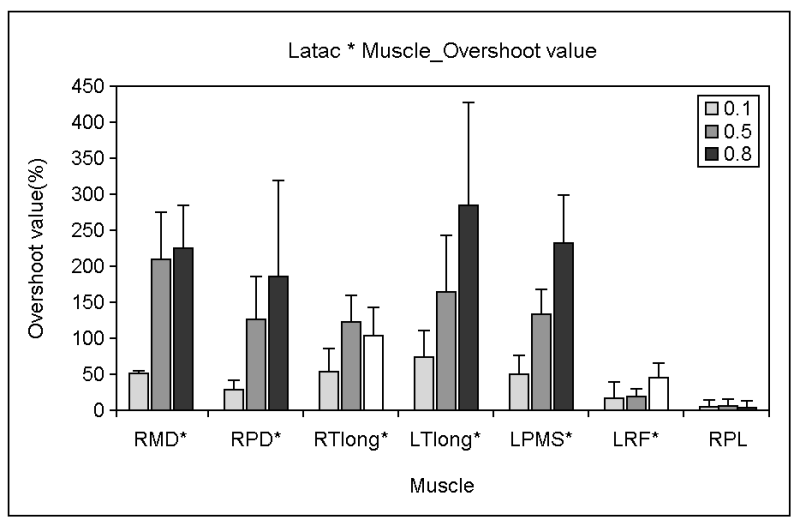

Figure 14. Interaction of lateral acceleration level and muscle [* denotes the statistically significance: i.e., $p<0.05$ ] 


\subsubsection{Overshoot value of vehicle motion data}

Vehicle motion의 overshoot value에 대한 분산분석 결 과, 차량 특성이나 중력가속도 또는 차량거동과 같은 어떠한 독립변수에 대해서도 통계적으로 유의한 차이를 보이지 않 았다.

\section{Discussion}

\subsection{Response time}

차량 특성과 중력가속도에 따른 차량거동 신호들의 response time을 분석한 결과, 차량거동에 따라서 통계적인 차이를 보였다. 사후분석 결과 YawVel가 가장 빠른 반응속 도를 보였고, LatAcc과 Roll은 반응시간이 통계적으로 차이 가 없는 것으로 나타났다. LatAcc과 Roll에 대해 통계적으로 는 반응시간의 차이가 없다고 나타났지만, 경향만을 보자면 YawVel, LatAcc, Roll 순으로 반응하는 것을 확인하였다. 이는 Yi et al. (2004)의 연구에서 언급하고 있는 Step input 시험에서의 차량의 운동 8단계(Step 1: 앞쪽 미끄럼 각; Step 2: 앞쪽 측면 힘; Step 3: 앞/뒤 횡력 차이로 인한 선수 동요운동(yawing); Step 4: 뒤쪽 타이어에 Yaw rate로 인한 미끄럼 각 발생 시작; Step 5: 뒤쪽에 횡력 발생 시작; Step 6: 무게중심에 원심력 작용; Step 7: 차체 rolling; Step 8: 선회외측으로의 하중이동)에서 언급한 바와 같이 유사한 반 응시간 순서 결과라고 할 수 있다. Yoon et al.(1994)의 연 구에서도 역시 현가장치가 다른 두 가지 조건의 차량을 대 상으로 한 step input 시험에서의 YawVel와 LatAcc, 그리 고 Roll의 response time 연구에서 두 가지 조건의 차량 모 두 YawVel, LatAcc, 그리고 Roll 순의 경향으로 결과 도출 이 되어, 본 연구의 결과와 유사한 결과로 확인되었다.

근육 신호에 대한 response time의 경우, $\mathrm{B}$ 차량에서 response time이 통계적으로 빠르게 나타났다. 우선, 근육 의 response time이 빠르다는 것은 운전자가 핸들링을 하는 동시에 운전자 근육이 빠르게 반응하는 것을 의미한다. 이는 다이나믹한 주행을 하는 차량 $\mathrm{B}$ 가 빠르게 움직임에 따라 운 전자의 근육 또한 빠르게 환성화 되는 것으로 해석할 수 있 을 것이다. 또한 근육 간의 response time 분석에서, 하지 근육인 좌측 대퇴직근(LRF)에서 가장 느린 response time 을 보인 반면, 우측 어깨 근육인 우측 측면삼각근(RMD)에 서 가장 빠른 response time을 보였다. Pick and Cole (2006)의 연구 결과에서 운전자가 핸들링을 할 때, 가장 많 이 활성화 되는 근육이 삼각근으로 나타났고, 본 연구에서는 가장 빠르게 반응하는 근육으로 나타났다. 다시 말하면, 삼
각근은 핸들링을 함에 있어 가장 많은 활성도를 보이고 직 접적으로 핸들링에 관여되는 근육인 동시에 response time 이 가장 빠르게 나타난 것이라 할 수 있을 것이다. 근육들의 response time에 대한 결과를 다른 관점으로 해석한다면, 핸들링에 직접적으로 관여하는 상지 근육과 자세 유지를 위 한 하지 근육으로 나누어 생각할 수 있을 것이다. 즉, 일반적 으로 상지 근육은 조향 입력에 많은 관여를 하는데 비해 하 지 근육은 자세 유지를 위해 근육이 활성화 되기 때문에 이 와 같은 결과가 도출된 것이라 사료된다.

차량 특성과 근육 간의 교호작용에서 통계적으로 유의한 결과를 보였고, 상지에 비해 하지 근육에서 차량거동에 따라 response time의 차이가 점차적으로 많이 나는 것을 확인할 수 있었다. 또한 차량거동에 따라 근육 각각에서 response time의 통계적 차이를 검증하기 위하여 근육 별 분산분석 을 시행한 결과, 오직 $\mathrm{LRF}$ 근육에서 $\mathrm{A}$ 차량 보다 $\mathrm{B}$ 차량의 response time이 통계적으로 빠르게 반응하였다(Figure 8). 좌측 다리는 일반적으로 운전자가 핸들을 급격히 돌렸을 때 몸의 쏠림으로부터 저항하기 위하여 왼발을 Foot rest에 올 려놓고 자세를 유지하게 되는데, 차량 특성에 따라 몸의 쏠 림 정도가 각각 다르므로 자세를 유지하는 $\mathrm{LRF}$ 근육은 차 량 특성을 반영하는 근육이라 할 수 있을 것이다. 추후 더 많은 차량을 대상으로 LRF 근육에 대한 response time을 측정 및 분석한다면 차량 특성을 규명하는데 있어 더욱 명확 한 변수가 될 것이라 예상된다.

\subsection{Peak Response time}

차량 특성과 중력가속도에 따른 차량거동 신호들의 peak response time을 구해 본 결과, $\mathrm{B}$ 차량이 $\mathrm{A}$ 차량 보다 통계 적으로 빠르게 나타나 response time과 유사한 결과를 보였 다. 차량거동에 따른 peak response time의 경우, response time의 결과 보다 더욱 명확히 세 차량거동이 모두 다른 그 룹으로 분류되어 YawVel, LatAcc, 그리고 Roll 순으로 나 타났다. Peak response time 또한 조향 입력에 따른 차량거 동의 반응시간을 의미하므로 Yi et al.(2004)의 Step input 시험에서의 차량의 운동 8단계에 해당된다.

근육 신호에 대한 peak response time의 경우, 차량거동 과 마찬가지로 $\mathrm{A}$ 차량 보다 $\mathrm{B}$ 차량에서 통계적으로 더 빠른 peak response time이 나타났다. 이는 다이나믹한 주행을 하는 차량 $\mathrm{B}$ 에서 차량 $\mathrm{A}$ 보다 빠른 peak response time이 나타나 response time의 근육에 결과와 유사하게 나타났 다. 결국, 차량의 반응속도에 운전자의 근육 반응속도는 전 반적으로 비례하다고 미루어 볼 수 있다. 근육에 따른 peak response time에 대한 결과로는 상지의 근육들이 하지의 근 육 보다 통계적으로 빠른 peak response time을 보여, 조향 
입력에 상지 근육이 모두 사용되는 반면에 하지 근육은 자세 유지를 위해 사용되기 때문에, 상지 근육 보다 느린 peak response time이 나타난 것이라 사료된다. 차량 특성과 근 육 간의 교호작용에서도 통계적으로 유의한 결과를 보였으 며, response time의 결과와 마찬가지로 상지 근육에 비해 하지 근육에서 차량 특성에 따라 peak response time이 차 이가 더 많이 나는 것을 확인하였다.

\subsection{Overshoot value}

차량 특성에 따른 근육 신호들의 overshoot value를 분산 분석한 결과, $\mathrm{B}$ 차량 보다 A 차량의 overshoot value가 통 계적으로 더 높게 나타났다. 이는 $\mathrm{B}$ 차량에서 근육의 최대 값(peak value) 과 정상 상태(steady-state) 간의 차이가 $\mathrm{A}$ 차량 보다 적다는 것을 의미한다. 또한 과도 상태에서 차 량의 쏠림이 $\mathrm{A}$ 차량 보다 $\mathrm{B}$ 차량이 적기 때문에 response time 또는 peak response time의 결과와 연관 지어 보면, 반응시간이 빠른 B 차량은 overshoot value 또한 낮게 나 타나 본 연구에서는 $\mathrm{A}$ 차량 보다 $\mathrm{B}$ 차량이 다이나믹한 주 행을 할 수 있는 차량임을 보여주고 있다. 중력가속도에 따 른 근육의 overshoot value는 중력가속도가 증가할 수록 overshoot value 또한 증가하는 결과를 보였다. 이는 중력 가속도가 커질수록 원심력이 더욱 커지기 때문에 차량의 쏠 림이 점차 심해지는 것으로 미루어 볼 수 있다. 근육 부위에 따른 overshoot value 결과를 보면, 상지 근육의 overshoot value는 높고, 하지 근육의 overshoot value는 낮게 나타났 다. 이 결과는 앞서 언급되었던 핸들링에 직접 관여하는 근 육인 상지 근육들이 핸들을 돌리기 위해 급격히 힘을 주는 양과 정상 상태에서 핸들을 유지하는 힘의 양이 차이가 많이 나기 때문이고, 하지 근육들의 경우는 핸들링에 직접 관여하 지 않고 자세만을 일정하게 유지하게 하기 때문에 최대값과 정상 상태와의 차이가 크지 않아 나타난 결과라 할 수 있다.

교호작용을 살펴보면, 차량 특성과 중력가속도 간의 교호 작용에서 통계적으로 유의한 결과를 보였고, 중력가속도가 증가함에 따라 $\mathrm{A}$ 차량과 $\mathrm{B}$ 차량의 overshoot value가 점차 차이가 많이 나는 경향을 보였다. 또한, 중력가속도와 근육 간의 교호작용에서도 통계적으로 유의한 결과를 보였다. 중 력가속도가 증가함에 따라 대부분 근육의 overshoot value 가 증가하는 경향을 보였고, 근육 별 분산분석을 시행한 결 과, 좌측 대흉근(LPMS)에서 중력가속도가 세 가지 그룹으 로 분류되어 중력가속도를 가장 잘 반영하는 근육으로 나타 났다. 상지 근육의 overshoot value 결과를 좌 - 우측으로 나누어 고려해 보면, 좌측 상지 근육은 핸들링할 때에만 많 은 근활성도를 보여 높은 overshoot value를 보인 반면, 우 측 상지 근육은 핸들링을 할 때뿐만 아니라 핸들을 유지할
때에도 근육이 활성화되기 때문에 좌측 보다는 우측 상지 근 육의 overshoot value가 전반적으로 낮게 나타나는 경향을 보이는 것이라 예상된다(Figure 14).

본 연구의 한계점으로는 우선, 실험에 참여한 피실험자의 인원을 들 수 있다. 비록 23년 이상의 전문 운전 경력을 가 지고 있어 실험 수행 능력이나 수행 시 긴장 및 불안정한 외부적 요소들이 일반 운전자들에 비해 매우 일관성 있는 결 과를 도출할 수 있다고 하더라도, 여전히 한계점을 가지고 있다. 다만, 본 연구의 목적으로 근전도 신호를 활용하여 차 량의 특성에 따른 운전자의 반응을 차량변수와 동시에 고려 하기 위하여 수행한 연구로써 연구의 방향성은 확인할 수 있었다고 할 수 있다. 이후 추후 연구로 보다 많은 전문 운 전자를 피실험자로 참여하여 본 연구 결과의 검증과 함께 결과의 일반화를 하고자 한다.

두 번째의 한계점이라고 한다면, 차량 특성을 결정하는 요 인이 타이어 휠의 지름과 스테빌라이져 바의 지름 외에도 많 은 변수가 있음에도 본 연구의 수행 한계로 인해 두 가지 요 인만을 고려한 점이라고 할 수 있을 것이다. 추후 연구에서 는 차량 특성을 결정하는 중요 요인을 분석하고 적용함으로 써 운전자의 반응과 차량거동 변수와의 상관관계를 연구해 야 할 것으로 사료된다.

끝으로, 차량의 특성에 따른 운전자의 생체 반응에 대한 연구에서 근전도 뿐만이 아닌, 다른 생체반응 신호에 대한 복합적인 연구가 수행되어야 한다고 사료된다.

\section{Conclusions}

본 연구는 ISO 7401의 신호분석 방법을 근전도 신호에 적용하여 step input 시험에서 운전자의 반응을 정량적으로 평가하고 또한 차량과 운전자를 모두 고려한 차량 성능 평가 의 기초 연구를 목적으로 두었다. 우선, Table 3은 본 연구 의 최종적 결과를 간략하게 나타내고, 어떠한 지표(차량거동 신호 또는 근전도 신호)가 차량 특성이나 중력가속도를 더 정확히 규명해 낼 수 있는지에 대해 나타내었다.

결과적으로 response time은 차량거동 신호보다 근전도 신호에서 차량 특성을 더 잘 반영하였고, 차량거동은 중력가 속도에 따라 통계적으로 유의하긴 하였지만, 세 가지 중력가 속도를 모두 구분할 수는 없었다. 최종적으로 근전도에서 좌 측 대퇴직근 $(\mathrm{LRF})$ 근육이 가장 차량 특성을 잘 반영하는 근육으로 도출되었다.

Peak response time의 경우, 차량거동 신호나 근전도 신 호 모두 차량 특성을 규명하기에 충분하다는 결과를 얻었다. 반면, 차량거동 신호는 중력가속도에 따라 통계적으로 차이 
Table 3. Summary of results for EMG and vehicle motion data for dependent variables

\begin{tabular}{|c|c|c|c|c|}
\hline & & Response time & Peak response Time & Overshoot value \\
\hline \multirow{3}{*}{ EMG data } & Vehicle type & A: $0.42 \mathrm{~s} ; \mathrm{B}: 0.22 \mathrm{~s}$ & A: $0.47 \mathrm{~s} ; \mathrm{B}: 0.41 \mathrm{~s}$ & A: $125 \%$; B: $89 \%$ \\
\hline & Muscle & $\begin{array}{l}\text { Upper-limb: } 0.09 \sim 0.20 \mathrm{~s} \\
\text { Lower-limb: } 0.20 \sim 0.34 \mathrm{~s}\end{array}$ & $\begin{array}{l}\text { Upper-limb: } 0.32 \sim 0.42 \mathrm{~s} \\
\text { Lower-limb: } 0.57 \sim 0.63 \mathrm{~s}\end{array}$ & $\begin{array}{c}\text { Upper-limb: } 94 \sim 180 \% \text {; } \\
\text { Lower-limb: 7 28\% }\end{array}$ \\
\hline & Lateral acceleration & N/S (not significant) & $\mathrm{N} / \mathrm{S}$ & $\begin{array}{c}\text { 0.1G: } 39 \% \text {; } 0.5 \mathrm{G}: 111 \% \text {; } \\
\text { 0.8G: } 154 \%\end{array}$ \\
\hline \multirow{3}{*}{$\begin{array}{l}\text { Vehicle } \\
\text { motion data }\end{array}$} & Vehicle type & & A: $0.52 \mathrm{~s} ; \mathrm{B}: 0.38 \mathrm{~s}$ & \multirow{3}{*}{$\mathrm{N} / \mathrm{S}$} \\
\hline & Motion variable & Yaw: 0.15; Lat: 0.24; R: 0.26s & Yaw: 0.27; Lat: 0.46; R: 0.59s & \\
\hline & Lateral acceleration & & 0.1G: .39s; 0.5G: .4s; 0.8G: .52s & \\
\hline \multirow{2}{*}{ Index } & EMG data & Better & Good & Better \\
\hline & Vehicle motion data & N/A & Better & N/A \\
\hline
\end{tabular}

를 보이긴 하였지만, 세 가지의 중력가속도를 명확히 규명하 지는 못하였다. 따라서, 차량거동 신호와 근전도 신호는 차 량 특성을 구분하는데 있어 모두 우수한 변별력을 가지고 있다.

Overshoot value는 차량거동 신호의 경우, 차량 특성이 나 중력가속도를 규명할 수 있는 어떠한 통계적 결과도 보 이지 않은 반면, 근전도 신호의 경우는 그와 반대로 차량 특성과 중력가속도를 모두 명확히 규명하기에 우수한 변별 력을 보였다. 그 중, 중력가속도를 가장 명확히 규명할 수 있는 근육은 좌측 대흉근(LPMS)으로 도출되었다.

본 연구에서는 step input 시험을 통하여 차량 특성과 중력가속도에 따른 차량거동 신호와 근전도 신호분석을 ISO 7401에 적용하여 차량 특성을 평가할 수 있는 지표가 될 수 있는지, 지표가 될 수 있다면 정량화 할 수 있는 차 량거동 변수나 근육을 파악하는데 목적을 두었으나, 다양 한 운전자 및 다양한 특성의 차량을 시험하지 않아 평가 결과의 일반화에 있어 다소 한계가 있다. 현재로서 가장 우 선적으로 진행되어야 할 연구는 근전도가 차량거동을 대체 할 수 있는 지표가 될 수 있을지에 대해 명확히 파악하는 것이고, 그 이후, 정확한 평가를 위해 다양한 피실험자와 여러 특성을 가진 차량들을 비교함으로써 운전자의 특성 및 차량 특성을 보다 정확하게 규명할 수 있는 근육을 파 악 할 수 있을 것이라 기대한다.

\section{References}

Babala, M., Kempen, G. and Zatyko, P., Trade-offs for vehicle stability control sensor set, Society of Automotive Engineers 34: 2002-01-1587, 2002.
Balasubramanian, V. and Adalarasu, K., EMG-based analysis of change in muscle activity during simulated driving, Journal of Bodywork and Movement Therapies, 11, 151-158, 2007.

Data, D. and Frigerio, F., Objective evaluation of handling quality, Proceedings of the Institution of Mechanical Engineers, Part D Journal of Automobile Engineering, 216(4), 297-305, 2002.

Gobbi, M., A k, k- $\varepsilon$ optimality selection based multi objective genetic algorithm with applications to vehicle engineering, Optimization and Engineering, 2012.

Hermens, H.J., Freriks, B., Merletti, R., Stegeman, D., Blok, J., Rau, G., Disselhorst-Klug, C. and Hägg, G., SENIAM: European Recommendations for Surface Electromyography. Enschede, The Netherlands: Ressingh Research and Development, 1999.

International Standard ISO 7401, Road vehicles-Lateral transient response test methods-Open-loop test methods, 2003.

Kang, D.O., Heo, S.J., Kim, M.S., Choi, W.C. and Kim, I.M., Robust design optimization of suspension system by using target cascading method, International Jounal of Automotive Technology, 13(1), 109 $-122,2011$.

Milliken, W.F. and Milliken, D.L., Race car vehicle dynamics, Society of Automotive Engineers, Warrendale, PA, 1995.

Perotto, A.O., Morrison, D., Delage, E. and Iazzetti J., Anatomical guide for the electromyographer: the limbs and trunk. 4th ed. Springfield: Thomas, 2005.

Pick, A.J. and Cole, D.J., Measurement of driver steering torque using electromyography, ASME Journal of Dynamic Systems, Measurement and Control, 128, 960-698, 2006.

Ryu, J. and Gerdes, J.C., Integrating inertial sensors with global positioning system (GPS) for vehicle dynamics control, Journal of Dynamic Systems, Measurement and Control, Transactions of the ASME, 126, 243-254, 2004

Senger, K.H. and Schwartz, W., The influence of a four wheel steering system on the stability behavior of a vehicle-driver system, International Journal of Vehicle Mechanics and Mobility, 17(1), 388 $-402,1988$. 
Sohn, W.H., Kim, H.S., Shim, J.S. and Heo, S.J., Experimental comparative analysis and subjective evaluation on the handling and stability characteristics of passenger cars, Transactions of the Korean Society of Automotive Engineers, 3(4), 30-40, 1995.

Svenson, A.L. and Hac, A., "Influence of chassis control systems on vehicle handling and rollover stability", Proceeding 19th International Technical Conference on the Enhanced Safety of Vehicles (ESV), Washington, D.C, 2005.

Takiguchi, T., Yasuda, N., Furutani, S., Kanazawa, H. and Hitoshi, I., Improvement of vehicle dynamics by vehicle-speed-sensing fourwheel steering system, SAE Technical Paper 860624, 1986.

Williams, D.E. and Haddad, W.M., Nonlinear control of roll moment distribution to influence vehicle yaw characteristics, IEEE Transactions on control systems technology, 3(1), 110-116, 1995.

Yi, J.M., Park, J.H. and Lee, D.H., A study on mechanism of vehicle response and analysis of rolling motion using step input test, Transactions of the Korean Society of Automotive Engineers, 9(2), 26-32, 2004.

Yoon, T.H., Kim, H.K. and Kim Y.C., "A study on the test of active suspension vehicle for performance evaluation", Proceeding of the KAMES 1994 Joint Symposium, 2 (pp. 23-29), 1994.

\section{Author listings}

Yong-Ku Kong: ykong@skku.edu

Highest degree: Ph.D., Industry Engineering, the Pennsylvania State University

Position title: Professor, Department of Industrial Engineering,

Sungkyunkwan University

Areas of interest: Ergonomic Product Design, Musculoskeletal Disorders

\section{Myung-Chul Jung: mcjung@ajou.ac.kr}

Highest degree: Ph.D., Department of Industrial Manufacturing Engineering, Pennsylvania State University

Position title: Associate Professor, Department of Industrial Engineering,Ajou University

Areas of interest: Work design, Ergonomics, Product development, Biomechanics

\section{In-Seok Lee: lis@hknu.ac.kr}

Highest degree: Ph.D., Department of Industrial Engineering, POSTECH Position title: Professor, Department of Civil, Safety and Environmental Engineering, Hankyong National University

Areas of interest: Ergonomics in Safety and Health, Agricultural Ergonomics, Accessible Design

Young-Jin Hyun: Jiny@hyundai.com

Highest degree: Mphil, University of Southampton Position title: Senior Engineer, Hyundai motor group Areas of interest: Vehicle dynamics, Automobile ergonomics

Chang-Su Kim: kcs77@hyundai.com

Highest degree: M.S., Department of Industrial Engineering, Ajou University

Position title: Research Engineer, Hyundai motor group

Areas of interest: Vehicle dynamics

Min-Tae Seo: smt850920@skku.edu

Highest degree: M.S., Department of Industrial Engineering, Sungkyunkwan University

Position title: M.S., Department of Industrial Engineering, Sungkyunkwan University

Areas of interest: Ergonomic Product Design, Musculoskeletal Disorders, Hand tools

Date Received : 2012-12-04

Date Revised :2013-04-17

Date Accepted : 2013-04-18 